\title{
RECARACTERIZAÇÃO DO SUBGÊNERO TOLTECIA PILSBRY COM DESCRIÇÃO DA CONOUILIOMORFOLOGIA E ANATOMIA DOS SISTEMAS EXCRETOR E REPRODUTOR DE PUNCTUM (TOLTECIA) PILSBRYI (SCOTT), N.COMB. (GASTROPODA, STYLOMMATOPHORA, PUNCTIDAE)
}

\author{
Álvaro Luís Müller da Fonseca ${ }^{1}$ \\ José Willibaldo Thomé ${ }^{1}$
}

\begin{abstract}
Recharacterization of the subgenus Toltecla Pilsbry with ConCHOMORPHOLOGY AND ANATOMY OF THE EXCRETORY AND REPRODUCTIVE SYSTEMS OF Punctum (TOLTECLA) PILSBRYI (SCOTt), N.COMB. (Gastropoda, STYLOMMATOPHORA, PUNCTIDAE). Conchomorphological and anatomic characteristics of species from Punctum (Toltecia) are presented and discussed. The brief recharacterization about the conchomorphology and internal anatomy of Toltecia with related species from this subgenus is presented. The data from this species are compared with other related species from Punctidae, Helicodiscidae and Charopidae. Punctum (Toltecia) pilsbryi, n.comb. is redescribed and its shells features was analyzed by SEM (Scanning Electron Microscope) and commented, as well as the shells dimensions; the anatomy of the excretory and reproductive systems are described too. The anatomic characteristics, mainly from excretory system, characterize Punctum (Toltecia) pilsbryi, n.comb. like Punctidae.

KEY WORDS. Punctidae, Gastropoda, Punctum (Toltecia) pilsbryi, n.comb., conchomorphology, systematics
\end{abstract}

Segundo PILSBRY (1946), Punctidae estaria restrita à região Holártica, com espécies ocorrentes do Alasca e Colúmbia Britânica até o México e Bermudas na América Central. RIEDEL \& WIKTOR (1974) citaram a ocorrência de Punctum pgymeum (Draparnoud, 1801) para o norte da Europa ocidental e sul da África, mencionando que essa espécie também ocorre na Ásia e na América do Norte. SolEM (1977) mencionou a ocorrência da família Punctidae principalmente na Austrália e Nova Zelândia, com raras ocorrências na África, América do Sul, Tahiti, Hawaii e na região Holártica. Climo (1978) e SolEM (1983) citaram a ocorrência de espécies para a Oceania (Nova Zelândia, Austrália e região insular do Pacífico). PARKInSON et al. (1987) comentaram que a família Punctidae é de ampla distribuição, só não ocorrendo na região tropical da Ásia e das Américas.

Estudos de FonseCA \& ThOMÉ (1993a, b) e FonseCA (1994) sobre algumas espécies de Endodontoidea, indicam que espécies de Punctidae, a despeito de

1) Laboratório de Malacologia, Instituto de Biociências, Pontifícia Universidade Católica do Rio Grande do Sul, Av. Ipiranga, 6681, prédio 12, 90619-900 Porto Alegre, Rio Grande do Sul, Brasil. Com bolsas e auxílios do CNPq, CAPES e FAPERGS. 
SOLEM (1977) e PARKINSON et al. (1987), também ocorrem mais abundantemente na região Neotropical ao sul da América do Sul (sul do Brasil, Uruguai e Argentina).

Quais características podem ser usadas seguramente para a determinação de espécies dessa família? Qual gênero, subgênero e quais espécies estariam relacionadas às formas ocorrentes no sul da América do Sul? A descrição da conquiliomorfologia e dos sistemas excretor e reprodutor de Punctum (Toltecia) pilsbryi (Scott, 1957), n.comb. e sua comparação com outras espécies juntamente com uma recaracterização do subgênero Toltecia Pilsbry, 1926, permitem a elucidação dessas questões.

Segundo SOLEM (1983), Punctidae compreende endodontóides pequenos ou diminutos, com esculturação apical (embrionária) espiral e uma combinação de macro e microesculturações radiais (costelas, costeletas e microcostelas) pósapicais (pós-embrinonárias). Essas esculturações variam com os táxons, assim como a forma e o número de voltas da concha. O perióstraco é monocromático ou variegado. Poucos grupos apresentam barreiras na abertura. O umbílico é aberto, com espiralamento crescente das voltas (aspecto perspectivo) perfeitamente visível. SOLEM (1977) apresentou um estudo detalhado da esculturação de Punctum Morse, 1864, pelo qual este gênero apresentaria concha aparentemente similar à de Striatura Morse, 1864 (Zonitidae).

Charopidae e Punctidae, de acordo com SolEm (1976, 1983), apresentam típico sistema excretor Sigmurethra. SolEM $(1976,1983)$ prosseguiu afirmando que as características anatômicas básicas de Punctidae são sistema excretor, apresentando rim constituído de dois lobos (direito e esquerdo) com praticamente o mesmo tamanho - esse aspecto do rim foi destacado como característico principal da família por BAKER (1927).

Segundo WÄCHTLER (1934) e NORDSIECK (1985), a parte posterior do rim dos Stylommatophora apresenta numerosas dobras da parede e, mais anteriormente, estas dobras ficam mais rasas e desaparecem no ápice. WÄCHTLER (1934) observou que a forma do saco renal é muito diversa, pode ser triangulóide, muito ou quase nada alongada, ou ainda curta e alargada; a porção apical pode estar curvada em direção ao reto, como ocorre nas espécies dos grupos dos Endodontidae. WÄCHTLER (1934) também observou que o saco renal, em alguns grupos, pode assumir a forma de ferradura como ocorre em Punctum.

Quanto ao sistema reprodutor, SolEM $(1976,1983)$ observou que os Punctidae são caracteristicamente sintremados e semidiáulicos. O ovotestis (ovariotestis) em geral com dois lobos em forma de gota (pingentes), podendo estar bem juntos ou moderadamente separados e subdivididos em várias extensões; o ducto hermafrodita (ovulispermioducto) não é entrecontorcido, ligando-se na face lateral do "talon" (complexo de fertilização) que apresenta uma cabeça (sic) globular (bolsa de fertilização); normalmente a genitália feminina é mais dilatada, apresentando próstata-útero (ovispermioducto) formando um conjunto amplo, parcial ou completamente fusionados e oviducto livre interligado à porção dilatada do tubo da espermateca (ducto da bolsa da copulação), sendo que a vagina e a 
espermateca são dotadas de pilastras lisas; complexo peniano (faliano) afilado e alongado, com inserção simples do músculo peniano (faliano retrator), internamente há uma porção epifálica derivada seguida de uma papila terminal e pilastras lisas, regulares ou irregulares.

Segundo PILSBRY (1946) o gênero Punctum apresenta as seguintes características principais: concha muito pequena, umbilicada, subdiscoidal, com espira convexa, unicolorida, esculturada por estrias oblíquas e delicadas, com ou sem costeletas espaçadas e estrias espirais convexas; a primeira 1 e $1 / 2$ volta é lisa ou estriada espiralmente de modo tênue, porém mais conspícua que nas voltas pós-embrionárias; a abertura é semilunar ou mais ou menos circular, com lábio simples e fino. Climo (1969) fornece como características de Punctum a concha geralmente com aspecto vítreo e a ausência de epifalo.

O subgênero Toltecia, segundo PILSBRY (1946), caracteriza-se por possuir concha dotada de costelas proeminentes e amplamente espaçadas, com várias costelas intercostelares menores, geralmente cinco ou mais. A anatomia interna, prosseguiu PILSBRY (1946, Fig. 349) seria basicamente aquela descrita por BAKER (1927) para Punctum (Toltecia) conspectum jaliscoense (Pilsbry, 1926).

PILSBRY (1946) afirmou que outras espécies apresentam características semelhantes à anterior e também são incluídas no subgênero Toltecia: $P$. (T.) vitreum Baker, 1930, P. (T.) conspectum conspectum (Bland, 1865), P. (T.) conspectum pasadenae (Pilsbry, 1896) e P. (T.) conspectum alleni (Pilsbry, 1919).

Quanto à anatomia interna de outras espécies de endodontóides neotropicais, os únicos trabalhos são os de BAKER (1927), PILSBRY (1946) - que transcreveu algumas descrições de Baker em 1927 e 1930 (apud PILSBRY 1946) SCOTT $(1964,1968,1970)$, VAZ (1991) e FonsECA (1994). SCOTT (ib.) trata das espécies Zilchogyra costellata Orbigny, 1935, Trochogyra leptotera (Mabille \& Rochebrune, 1882), Stephanoda mirabilis Scott, 1968, Stephadiscus lyrata (Gould, 1846) e Stephadiscus testalba (SCOTT 1970); VAZ (1991) comenta as espécies Trochogyra pleurophora (Moricand, 1846) e Ptychodon janeirensis (Thiele, 1927). BAKER (1927) descreve a anatomia de Radiodiscus millecostatus Pilsbry \& Ferris, 1906 e Radioconus bactricolus Baker, 1927, que ocorrem na América do Norte; Baker, 1930 (apud PILSBRY 1946) apresenta Radiodomus abietum Baker, 1930, cujo gênero ainda não possui registro para a América do Sul. FonsECA (1994) trata de espécies de Charopidae: "Radioconus" costellifer (Scott, 1957), Radioconus riochicoensis (Crawford, 1939), Radiodiscus thomei Weyrauch, 1965 (também apresentada por FONSECA \& THOMÉ 1994) e uma de Punctidae: P. (T.) pilsbryi, n.comb., descrita originalmente como Radiodiscus pilsbryi Scott, 1957.

\section{MATERIAL E MÉTODOS}

A coleta de exemplares de Punctum (Toltecia) pilsbryi (Scott, 1957), foi feita em matas subtropicais úmidas, próximas a rios ou regatos, no Parque Saint-Hilaire, Viamão; na Fazenda São Maximiano, BR116, km 307, Guaíba; no Parque Bento Gonçalves, Cristal; na localidade dos Galpões em Camaquã; no 
Parque do Caracol em Canela e nas margens da RS20, a 10km de São Francisco de Paula, Rio Grande do Sul, Brasil.

Os espécimes foram encontrados entre a serapilheira de matas com vegetação abundante, grande quantidade de húmus, folhas e umidade regular. Micromoluscos, em geral, ocorrem em maior densidade nos locais da mata onde a umidade é acentuada, o folhedo é alto e a quantidade de serapilheira é muita, sendo facilmente encontrados no sopé de árvores frondosas. Dificilmente ocorrem em locais onde a vegetação é esparsa.

Em laboratório a serapilheira foi submetida a uma triagem sob lupa de mesa e os exemplares foram anestesiados em solução de mentol. Eventualmente, os animais não completamente distendidos foram mantidos sob refrigeração $\left( \pm 6^{\circ} \mathrm{C}\right)$ por no máximo $24 \mathrm{~h}$. Uma vez anestesiados, os espécimes foram determinados, separados em lotes, fixados e conservados em álcool $70 \%$ conforme a metodologia de Fonseca (1994) e FonseCA \& Thomé (1994b).

Foram usados quatro espécimes de $P$. (T.) pilsbryi (Scott, 1957) para a conquiliomorfologia e outros quatro para o estudo das partes moles. Os espécimes examinados foram doados à coleção do Museu de Ciências Naturais da Fundação Zoobotânica do Rio Grande do Sul.

A dissecação do material fixado foi feita ao estereomicroscópio com câmara lúcida. Conchas de dois espécimes foram analisadas e fotografadas ao microscópio eletrônico de varredura (MEV).

As medidas dos órgãos e sistemas foram realizadas, com o uso da ocular micrométrica do estereomicroscópio e as das esculturações e microesculturações da concha foram obtidas a partir das escalas das fotomicrografias ao MEV, utilizando a metodologia descrita por FonsECA (1994) e FonsECA \& THOMÉ (1994b).

O método de conquiliometria utilizado foi aquele de FONSECA (1994) e FONSECA \& THOMÉ (1994b). Foram tomadas as seguintes medidas das conchas, em milímetros, com a ocular micrométrica do estereomicroscópio: $\mathbf{D}=$ diâmetro maior da concha, $\mathbf{d}=$ diâmetro menor da concha, du=diâmetro do umbílico, $\mathbf{h}=$ altura da concha, ha= altura da abertura, $\mathbf{h e}=$ altura da espira, $\mathbf{l a}=$ largura $\mathrm{da}$ abertura.

\section{RESULTADOS}

\section{Punctum (Toltecia) pilsbryi (Scott, 1957), n.comb.}

Radioconus pilsbryi Scott, 1957: p.14-16

Radiodiscus misionensis Scott, 1957: p.80-83

Zilchogyra cleliae Weyrauch, 1965: p.124.

\section{Conquiliomorfologia (Figs 1a-f)}

Punctum (Toltecia) pilsbryi espécie de tamanho médio em relação às demais espécies do gênero, apresenta concha cônico-patulóide, com espira muito pouco elevada, de ápice obtuso. O crescimento das voltas é regular e relativamente 

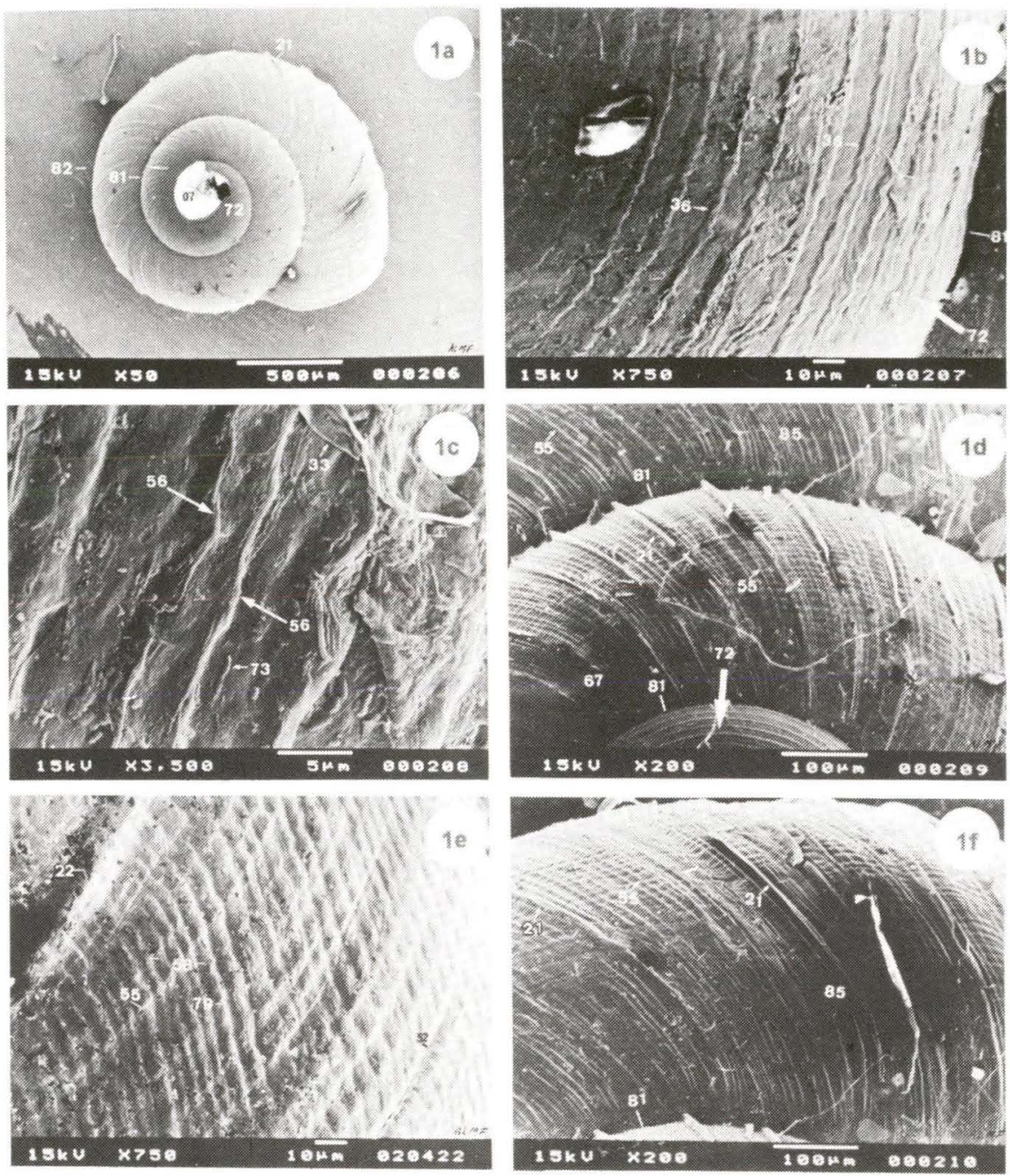

Fig. 1. Punctum (Toltecia) pilsbryi. (a) vista dorsal de um espécime de com ápice da concha danificado; (b) detalhes da microesculturação embrionária; (c) detalhes da microesculturação embrionária; (d) detalhe da penúltima volta e parcial da protoconcha e última volta; (e) detalhe da última volta; (f) detalhe da microesculturação pós-embrionária. (07) Ápice da concha, (21) costela, (33) enrugamento do perióstraco, (36) estria, (55) microcostela, (56) microestria, (58) ondulação do perióstraco, (67) penúltima volta, (72) protoconcha, (73) protuberância do perióstraco, (79) sulco do perióstraco, (81) sutura, (82) teleoconcha, (85) última volta.

rápido, apresentando 3 e $1 / 2$ a 4 voltas em 2,0 a 2,4mm. O perióstraco, de aspecto vítreo, é amarelado (semitransparente ou opaco) a castanho-ocre. A protoconcha apresenta estrias contínuas (Fig. 1b), bem deprimidas; as demais voltas apresentam costelas altas, finas e laminares (Figs 1a,d,f). 
A 1 e 1/2 volta inicial (embrionária), constitui a protoconcha, destacando-se da espira, a qual não é perfeitamente delimitada, embora seja bem visível. Há de 15 a 17 estrias nepiônicas muito deprimidas, tênues, irregulares e de aspecto retorcido. Em grandes aumentos (3500X, Fig. 1c) percebe-se que as estrias embrionárias são constituídas por dois filamentos retorcidos, finíssimos, paralelos e separados por não mais do que $3 \mu \mathrm{m}$; não se apresentam muito afastadas entre si (uma a cada $10 \mu \mathrm{m}$ ) e o espaço entre as estrias é de relevo irregular, apresentando leves ondulações e protuberâncias. A sutura das voltas nepiônicas é apertada, profunda e perfeitamente nítida desde o ápice.

A teleoconcha é constituída de 2 a 2 e 1/2 voltas, apresenta sutura profunda, bem marcada e um pouco acanalada devido ao contorno acentuadamente convexo das voltas (Figs 1a, 1d). A esculturação é esparsa com 10 costelas por $500 \mu \mathrm{m}$, as quais são altas, simples, laminares, um pouco inclinadas no sentido dextrógiro e de traçado mais convexo que sigmóide (Figs 1a, 1d, 1f). As costelas das primeiras voltas pós-embrionárias são mais conspícuas, sendo de difícil distinção em especial na última volta. Contam-se de 30 a 32 costelas na penúltima volta e de 33 a 35 , na última. Nas primeiras voltas pós-embrionárias e parte da penúltima, a microesculturação é melhor definida que no restante da penúltima e na totalidade da última volta. Eventualmente ocorrem costeletas um pouco maiores que as microcostelas. As microcostelas (Figs 1d, 1e, 1f), muito finas, tênues e paralelas entre si, são posicionadas a intervalos pouco regulares (mais ou menos uma a cada $9 \mu \mathrm{m}$, constituindo de seis a 12 filetes entre as costelas). Na última volta, essas microcostelas tornam-se menos definidas e ocorrem a intervalos mais irregulares. Toda a superfície da teleoconcha está gravada por uma microestriação (espiral) tênue e deprimida. Em grandes ampliações (750X, Fig. 1e) percebe-se que essa microestriação é composta por ondulações serpenteantes do perióstraco, ocasionadas por leves sulcos também serpenteantes e aparentemente paralelos entre si (mais ou menos uma a cada $7 \mu \mathrm{m}$ ). A superfície dos espaços entre as microesculturas não é totalmente lisa, embora seja regular.

A última volta apresenta um diâmetro mais amplo à medida que se aproxima da abertura, praticamente dobrando seu diâmetro inicial e resultando em uma abertura muito ampla, mais larga que alta, de formato mais circular que reniforme e um pouco deprimida na face dorso-palatal. O peristômio é simples e cortante. $\mathrm{O}$ umbílico é profundo, perspectivo e um pouco aberto (1/5 do D). Dimensões: $\mathrm{D}=2,0$ a $2,4 \mathrm{~mm} ; \mathrm{d}=1,7$ a $2,0 \mathrm{~mm} ; \mathrm{du}=0,5 \mathrm{~mm} ; \mathrm{h}=1,1$ a $1,4 \mathrm{~mm}$; he $=0,2 \mathrm{~mm}$; ha $=0,5 \mathrm{~mm} ; \mathrm{la}=0,7 \mathrm{~mm}$.

\section{Sistema Excretor (Fig. 2a)}

O rim posiciona-se posteriormente na cavidade palial, anterior à glândula do albume e à alça terminal do intestino posterior, entre o reto à direita e o pericárdio à esquerda. O tegumento ao qual está aderido, apresenta-se pigmentado na face dorsal por esparsas pontuações nodoadas escuras. Possui formato trapezóide, mas profundamente fendido na face distal. É mais alto $(0,71 \mathrm{~mm})$ do que largo $(0,42 \mathrm{~mm})$, equivalendo a pouco menos de $2 / 5$ da cavidade palial. Tem cor esbranquiçada, esmaecida e aspecto debilmente granuloso devido às dobras muito 

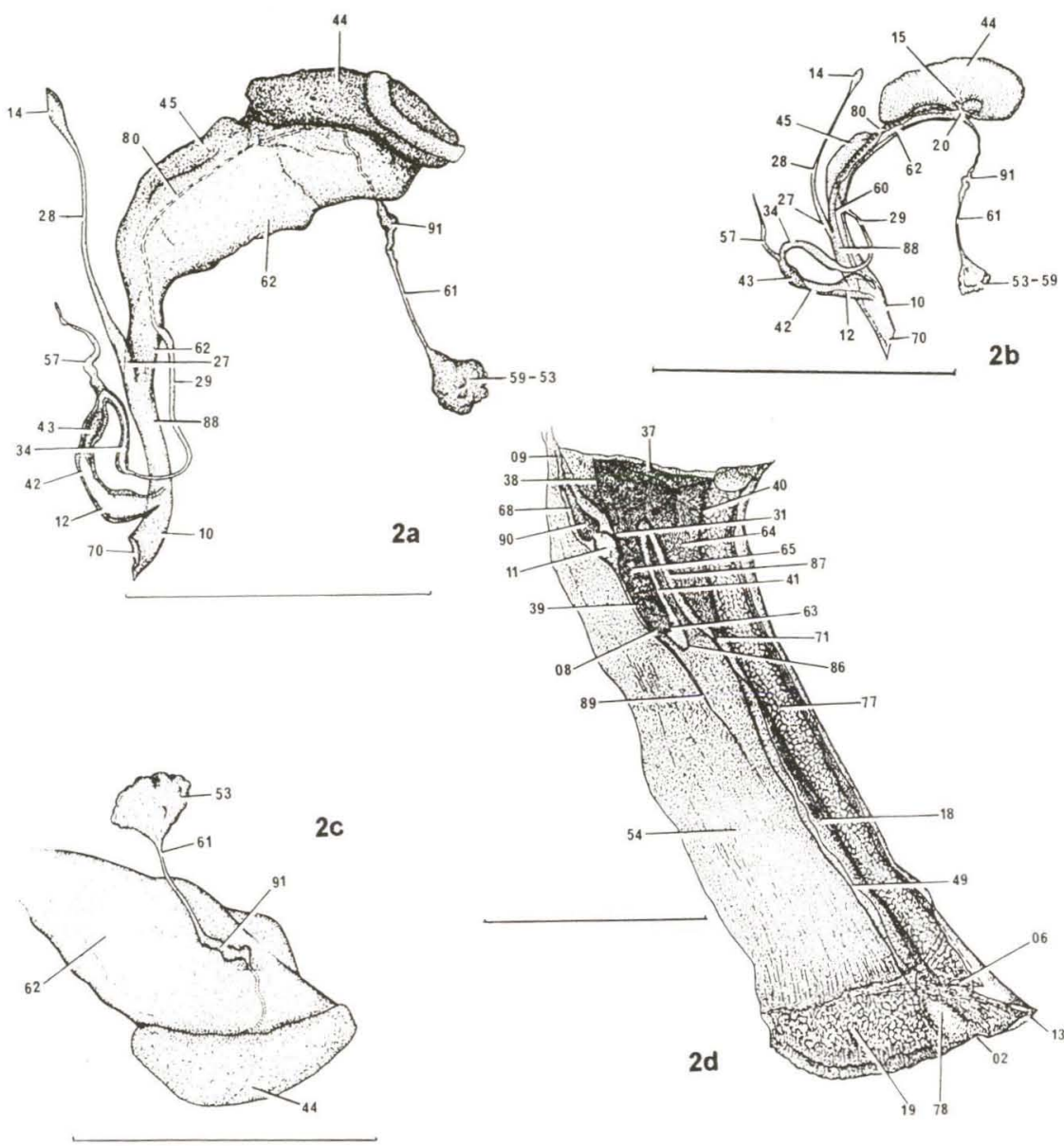

$59-53$

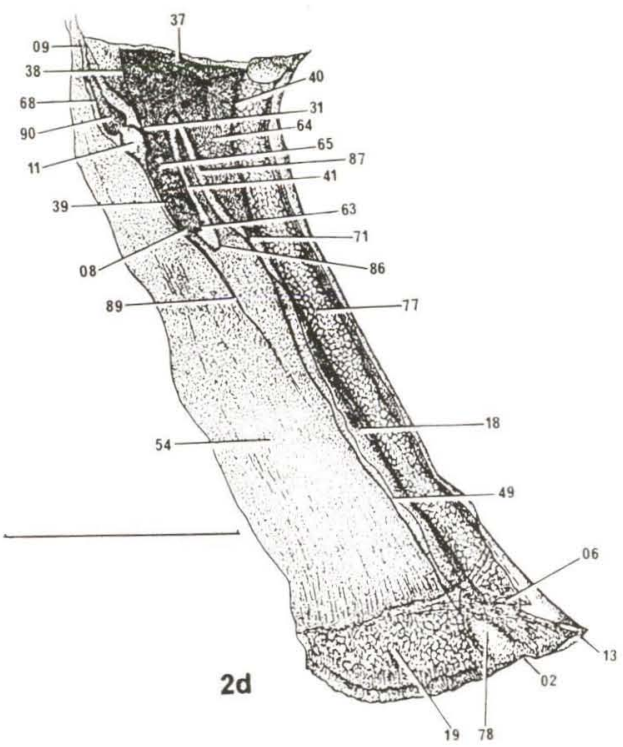

Fig. 2. Punctum (Toltecia) pilsbryi. (a) cavidade palial; (b) sistema reprodutor em vista látero-dorsal; (c) vista lateral do sistema reprodutor de um espécime jovem; (d) vista látero-ventral da região mediana do sistema reprodutor, mostrando o ovispermioducto com canal oviducal intumescido (canal incubador). (02) Abertura excretora, (06) ânus, (08) ápice do rim, (09) artéria aórtica, (10) átrio genital. (11) aurícula, (12) bainha faliana, (13) prega do pneumostômio, (14) bolsa da copulação, (15) bolsa de fertilização, (18) canal excretor, (19) colarinho do manto, (20) complexo de fertilização. (27) dilatação distal do ducto da bolsa da copulação, (28) ducto da bolsa, (29) ducto deferente, (31) ducto reno-pericárdico, (34) epifalo, (37) face intestinal do rim, (38) face pericárdica, (39) face pulmonar, (40) face retal, (41) face uretal, (42) falo, (43) falo propriamente dito, (44) glândula do albume, (45) glândula prostática, (49) lamela do canal excretor, (53) lobo do ovariotestis, (54) manto pulmonar. (57) músculo retrator faliano, (59) ovariotestis, (60) oviducto, (61) ovulispermioducto, (62) ovispermioducto, (63) papila renal, (64) parte direita do rim, (65) parte esquerda, (68) pericárdio, (70) poro genital, (71) poro uretal, (77) reto, (78) sinus excretor, (80) sulco espermático, (86) ureter primário, (87) ureter secundário, (88) vagina, (89) veia pulmonar, (90) ventrículo, (91) vesícula seminal. Escala $=1 \mathrm{~mm}$. 
pouco profundas. Visualmente, não aparenta estar dividido em regiões distal e proximal, mas em duas regiões laterais: uma à esquerda (pericárdica) e outra à direita (retal). Na parte distal, o ureter primário insere sua face truncada no ápice da parte pericárdica (à esquerda), que adentra o ureter, formando pequena papila através de um débil septo, posterior à uma redobra inicial daquele, constituindo-se no poro renal. Na face esquerda da porção pericárdica, na altura da aurícula, hâ uma pequeníssima e débil prega que corresponde ao ducto reno-pericárdico. Distalmente, a mesma face é percorrida pela veia pulmonar, que se lança, de junto do ápice do rim, pelo manto pulmonar inclinando-se à direita, e tornando-se muito tênue logo a seguir.

A redobra inicial da face truncada do ureter primário, atinge o ápice da parte pericárdica do rim em sua face anterior e não pela direita. Proximalmente na face uretal dessa redobra, aloja-se o poro renal, donde o ureter estende-se para trás, encaixando-se numa profunda e estreita fenda até dobrar-se, de forma brusca, numa dobra fechada e seguindo-se pelo ureter secundário. É longo, apresentando $0,50 \mathrm{~mm}$ de comprimento e diâmetro de $0,03 \mathrm{~mm}$.

$\mathrm{O}$ ureter secundário ladeia a face esquerda da porção retal do rim, muito pouco encurvado, até seu ápice adjunto ao reto. Nesta altura abre-se num longo e amplo canal excretor através do poro uretal. Esse ureter possui o mesmo diâmetro $(0,03 \mathrm{~mm})$ e quase que o mesmo comprimento que o primário $(0,47 \mathrm{~mm})$. É esbranquiçado, da mesma tonalidade que aquele.

O canal excretor apresenta-se longo $(1,31 \mathrm{~mm})$, o que corresponde a $2 / 3$ do comprimento da cavidade palial e é mais amplo que o diâmetro do ureter secundário $(0,07 \mathrm{~mm}$ de largura $)$, quase o dobro. Esse canal inicia-se junto ao ápice da porção direita (retal) do rim, percorrendo toda a extensão adjacente do reto até se abrir para o sinus excretor, ao lado do ânus. Sua face esquerda comporta uma membrana, semelhante a uma lamela ou aba, que encobre o sulco apoiando-se no reto até o sinus.

O poro uretal é posterior, posicionando-se medianamente na cavidade palial, onde se inicia o canal excretor. Através desse poro exterioriza-se o ureter secundário.

O sinus excretor é uma continuação do canal excretor. Inicia-se ao lado do ânus, como um sulco raso, afunilado e efuso, estando encoberto em parte pela prega do pneumostômio e um pouco inclinado à direita. A abertura excretora ocorre junto à borda do colar do manto, como um leve afinamento da espessura dessa borda.

\section{Sistema Reprodutor (Figs $2 b-d$ )}

O ovariotestis está amplamente intrometido na glândula digestiva posterior, ocupando quase que metade de seu espaço. É de cor leitosa, contrastando levemente à castanha-amarelada e muito clara da glândula digestiva. É simples (um lobo), compacto, de ácinos cujo tamanho é maior do que os da glândula do albume, conferindo-lhe aspecto granuloso. Apresenta forma de punho cerrado, com $0,21 \mathrm{~mm}$ de comprimento e $0,28 \mathrm{~mm}$ de largura (praticamente metade da glândula digestiva anterior). A porção da glândula digestiva que comporta o ovariotestis, 
possui pontuações (nódoas) escuras e esparsas no epitélio que recobre a glândula. $\mathrm{O}$ ovulispermioducto parte diretamente do ovariotestis, na altura do início do intestino posterior, percorrendo sua face columelar até a glândula do albume. Apresentando quase o mesmo comprimento do ducto da bolsa da copulação $(0,78 \mathrm{~mm})$, ou seja, praticamente $1 / 4$ de todo o sistema reprodutor. Sua parte distal corresponde à $1 / 3$ de seu comprimento total e é tão fina quanto o ducto da bolsa da copulação $(0,01 \mathrm{~mm})$. Tem cor esbranquiçada iridescente e é ondulado ao longo de sua extensão. Dilata-se em sua porção mediana, dando origem à vesícula seminal. Continua-se num ducto mais fino que o anterior e acomoda-se medianamente na face ventral da glândula do albume através do complexo de fertilização.

A vesícula seminal apresenta-se bem ondulada, mais dilatada distalmente e afilando-se de forma abrupta, num ducto que segue ao complexo de fertilização. Posiciona-se na parte mediana do ovulispermioducto e corresponde a pouco menos de $1 / 3$ da extensão deste $(0,24 \mathrm{~mm})$, com até quatro vezes o seu diâmetro $(0,04 \mathrm{~mm})$. Possui cor iridescente mais acentuada que a do ducto.

O complexo de fertilização (Fig. 2b) é composto por uma região proximal esferóide, que se comunica com a glândula do albume, e uma distal que se afina num pequeníssimo divertículo dorsal, o qual recebe o ovulispermioducto na parte ventral e pela distal liga-se ao ovispermioducto. É muito reduzido, possui $0,09 \mathrm{~mm}$ de comprimento e $0,03 \mathrm{~mm}$ de diâmetro. Apresenta cor esbranquiçada. Está todo envolvido pela glândula do albume e dele parte o sulco espermático, internamente ao ovispermioducto.

A glândula do albume é ovóide e bem deprimida. Apresenta cor leitosa. É composta por um aglomerado de ácinos, pouco distintos, levemente menores do que os do ovariotestis mas que mesmo assim conferem um aspecto granuloso à sua superfície. Está posicionada antes da glândula digestiva e intestino anteriores, logo após o rim. Proximalmente, por sobre sua face dorsal, encurva-se a alça terminal do intestino posterior (Fig. 2d) e a parte ventral aloja o complexo de fertilização. Equivale a $1 / 6$ do comprimento total do sistema reprodutor $(0,70 \mathrm{~mm})$ e a largura corresponde a metade do seu comprimento $(0,35 \mathrm{~mm})$.

O ovispermioducto (Fig. 2b) é longo (1,00mm) e pouco amplo $(0,15 \mathrm{~mm})$, contudo, quando o animal está em fase de oviposição (grávido) dilata-se, constituindo um canal incubador (Figs 2c,d), que apresenta quase a mesma largura da glândula do albume $(0,35 \mathrm{~mm})$, afunilando-se na porção distal. Sua extensão corresponde a praticamente $1 / 3$ da de todo o sistema reprodutor. Seu terço proximal está aderido na face ventral da glândula do albume, encaixando-se no complexo de fertilização. É esbranquiçado e semitransparente. Internamente percebe-se, de forma nítida, o sulco espermático dorsal, adjunto à glândula prostática e que se desvia para o lado ventral, continuando-se no ducto deferente. A face ventral é ocupada pelo canal oviducal ou canal incubador (quando da elaboração das camadas protetora e nutritiva dos ovos e posterior incubação), o qual penetra pelo oviducto até a altura da vagina. A parede interna deste canal, apresenta tênues sulcações e aspecto aveludado. O sulco alospermático não foi visualizado. Em sua porção distal, a face dorsal, comporta a glândula prostática na face externa. 
A glândula prostática (Figs $2 b$,d) percorre a face dorsal distal do ovispermioducto. Proximalmente, é engrossada e possui uma face truncada. Torna-se mais delgada distalmente, próximo do ducto da bolsa da copulação. É reduzida, deprimida $(0,08 \mathrm{~mm}$ de largura) um pouco alongada $(0,57 \mathrm{~mm})$, o que corresponde a mais ou menos metade do ovispermioducto. Constitui uma massa densa e esbranquiçada, de ácinos muito finos, fortemente aderida ao ovispermioducto, o qual é percorrido pelo sulco espermático em sua face interna e que se justapõe à essa glândula.

O oviducto é muito curto $(0,17 \mathrm{~mm})$ e delgado $(0,11 \mathrm{~mm})$, correspondendo a 1/7 do ovispermioducto, apresentando a mesma coloração esbranquiçada. Está posicionado entre as inserções dos ductos deferente e da bolsa da copulação, o primeiro inserido ventralmente e o segundo dorso-lateralmente. A face interna apresenta um sulco látero-dorsal (alospermático?) e aspecto aveludado.

$\mathrm{O}$ ducto da bolsa da copulação insere-se látero-dorsalmente logo após a vagina. Possui uma região proximal ampla $(0,05 \mathrm{~mm}$ de diâmetro), adelgaçando-se a seguir nas regiões mediana e distal do ducto $(0,01 \mathrm{~mm}$ de diâmetro), tornando-se um pouco mais fino que o ducto deferente. Possui $0,86 \mathrm{~mm}$ de comprimento, o que equivale a pouco menos de $1 / 3$ da extensão total do sistema reprodutor. Esse ducto estende-se pela face látero-dorsal da glândula prostática até atingir a face lateral esquerda anterior da glândula do albume, onde se aloja a bolsa da copulação. A bolsa é esbranquiçada, lanceolada e levemente deprimida. Possui $0,16 \mathrm{~mm}$ de comprimento e $0,04 \mathrm{~mm}$ de largura.

A vagina posiciona-se entre a inserção do ducto da bolsa da copulação e o átrio genital. É esbranquiçada, pouco semitransparente, alongada $(0,36 \mathrm{~mm}$ de comprimento), equivalendo a $1 / 7$ do comprimento de todo o sistema, e um pouco mais afilada $(0,07 \mathrm{~mm}$ de diâmetro) que o oviducto. A parede interna é simples, de aspecto aveludado, sem sulcações aparentes.

O ducto deferente é uniformemente afilado em quase toda sua extensão $(0,02 \mathrm{~mm}$ de diâmetro), sendo um pouco mais amplo que o ducto da bolsa da copulação. Sofre uma dilatação muito breve em sua inserção proximal $(0,03 \mathrm{~mm})$, entre o ovispermioducto e o oviducto, onde se continua internamente no sulco espermático. Apresenta $0,70 \mathrm{~mm}$ de extensão, ou seja, pouco mais de $1 / 4$ do comprimento total do sistema reprodutor. Volteia a vagina, próximo do átrio genital, ligando-se a mesma por uma finíssima comissura. Dá prosseguimento à extremidade proximal do epifalo, a qual está nitidamente constrita. É esbranquiçado e semitransparente.

O epifalo é menor que o falo ( $2 / 3$ deste), apresentando $0,42 \mathrm{~mm}$ de comprimento. É dilatado, tendo até $0,04 \mathrm{~mm}$ de diâmetro. Possui a mesma coloração esbranquiçada do falo e tem parede transparente como aquele. Sua extremidade proximal possui uma breve dilatação, acompanhada iminentemente de uma constrição, da qual se continua o ducto deferente. Apresenta-se mais amplo na parte distal, com uma dilatação que se continua no falo. Muito próximo dessa dilatação, há um dobramento acentuado em cujo ápice insere-se o músculo retrator faliano, que é fino $(0,03 \mathrm{~mm}$ de largura $)$ e longo $(0,5 \mathrm{~mm}$ de comprimento $)$. $\mathrm{Na}$ 
face interna, o epifalo constitui-se num simples ducto, cuja parede apresenta aspecto tenuamente aveludado.

O falo é longo $(0,64 \mathrm{~mm})$, equivalendo a pouco menos de $1 / 4$ do comprimento de todo o sistema reprodutor. É afilado na parte proximal $(0,06 \mathrm{~mm}) \mathrm{e}$ dilatado distalmente $(0,11 \mathrm{~mm}$ de diâmetro). A extremidade proximal apresenta uma leve dilatação, continua-se do epifalo e comporta, internamente, uma pequena massa ovóide, esbranquiçada e densa, que corresponde ao falo propriamente dito. Este possui face anterior truncada, com abertura estreita e elipsóide. A parede da bainha (porção distal) simples, de aspecto aveludado e abre-se no átrio genital.

$\mathrm{O}$ átrio genital é um pouco mais dilatado que a vagina $(0,12 \mathrm{~mm})$, contudo é bem mais curto $(0,18 \mathrm{~mm})$, correspondendo a $1 / 3$ da extensão da vagina (ou seja $1 / 15$ de todo o sistema reprodutor). Prolonga-se da vagina, na altura da inserção do falo, e abre-se para o poro genital.

O poro genital é pouco amplo em relação ao átrio genital. Possui $0,12 \mathrm{~mm}$ de diâmetro. Abre-se na face lateral da região cefálica, junto da base do omatóforo direito e logo abaixo do pneumostômio.

\section{DISCUSSÃO}

Em relação às demais espécies do gênero, Punctum (Toltecia) pilsbryi apresenta concha de tamanho médio, mas é grande se comparada às dos outros gêneros relacionados: Radioconus, Radiodiscus, Zilchogyra. Contam-se de 3 e 1/2 a 4 voltas em até $2,4 \mathrm{~mm}$ de diâmetro, enquanto que SCOTT (1957a) atribuiu-lhe 3 e $1 / 2$ voltas com $D=1,9 \mathrm{~mm}$ e Weyrauch (1965), 3,8 voltas e $\mathrm{D}=1,9 \mathrm{~mm}$. As espécies de Toltecia sec. PILSBRy (1946), apresentam de 1,38 a 2,4mm de diâmetro, entre 4 e 4 voltas e 1/4. Dentre essas dimensões, $P$. (T.) pilsbryi aproxima-se mais às de $P$. (T.) conspectum alleni (Pilsbry, 1919). O perióstraco varia de amarelo a costanho-ocre, mais ou menos semitransparente, como observaram FONSECA \& THOMÉ (1994a) para $P$. (T.) pilsbryi, mas segundo SCOTT (1957a), seria amarelo-dourado e semitransparente, podendo ser opaco de acordo com Weyrauch (1965). Pilsbry (1946) mencionou que o perióstraco dos Punctum apresenta coloração uniforme, cujo aspecto pode va riar de córneo à vítreo no subgênero Toltecia. Climo (1969), comentou que o perióstraco de Punctidae geralmente apresenta esse aspecto vítreo. Essas características são observáveis em $P$. (T.) pilsbryi e "Radioconus" costellifer, contudo, essa última espécie apresenta peculiaridades anatômicas internas que não a caracterizam como Punctidae. A protoconcha de $P$. (T.) pilsbryi apresenta 15 a 17 estrias - FONSECA \& THOMÉ (1994a) mencionaram a ocorrência de 15 estrias somente - semelhantes às de "Radioconus" costellifer e Radioconus riochicoensis, contudo, em grandes aumentos (3500X, Fig. 1c) percebe-se que são um pouco diferentes das dessas duas espécies, sendo, cada uma delas, compostas por finíssimas microestrias deprimidas, paralelas e muito juntas entre si. Nas espécies mencionadas por PILSBRY (1946), ocorre, segundo este autor, protoconcha levemente estriada ou lisa. P. (T.) vitreum Baker, 1930 apresenta ápice pregueado mas aparentemente liso, enquanto que em $P$. (T.) conspectum conspectum (Bland, 1865) e nas outras 
espécies: $P$. (T.) conspectum pasadenae (Pilsbry, 1896), $P$. (T.) conspectum alleni (Pilsbry, 1919) e P. (T.) conspectum jaliscoense (Pilsbry, 1926), apresentam-no aparentemente liso. Segundo PILSBRY (1946), um exame mais detalhado da protoconcha dessas espécies de Toltecia, demonstra que é finamente estriada, isto foi comprovado em $P$. minutissimum (Lea, 1841) por SOLEM (1977) e em $P$. (T.) pilsbryi por FONSECA (1994) pela análise da protoconcha ao MEV, e também no presente trabalho. Deste modo, verifica-se que a protoconcha às vezes é aparentemente lisa, mas num exame mais acurado demonstra-se estriada, como é o caso das variedades de $P$. (T.) pilsbryi: "misionensis" (Scott, 1957, sec. FONSECA \& THOMÉ 1995) e "cleliae" (Weyrauch, 1965, sec. FonsECA \& THOMÉ 1995).

As voltas pós-embrionárias de $P$. (T.) pilsbryi apresentam contorno mais convexo do que nas demais espécies anteriormente mencionadas. A costelação é esparsa, embora segundo FONSECA (1994), não tanto quanto em "Radioconus" costellifer, apresentando uma das mais baixas freqüências de costelas entre as espécies relacionadas. Estas são isoladas, não se constituindo em tríades como na maioria das espécies e assemelhando-se àquelas de "Radioconus" costellifer, contudo não são tão inclinadas. Há de 30 a 32 costelas na penúltima volta e de 33 a 35 na última, sendo uma das espécies relatadas que apresentam menor número de costelas por volta. SCOTT (1957a) mencionou que ocorrem 35 costelas na última volta, já WEYRAUCH (1965), observou de cinco a sete costelas por milímetro nessa volta. Apesar de geralmente haver uma maior freqüência de costelas por milímetro, contadas na região mediana da segunda volta (conforme o método de FONSECA 1994 e FONSECA \& THOMÉ 1994b), em comparação aos índices conquiliométricos apresentados pelos espécimes de WEYRAUCH (1965). Isto ocorre certamente porque WEYRAUCH (1965) empregou um método de contagem diferente do usado por FonseCA (1994) e FonseCA \& THOMÉ (1994b). PILSBRY (1946) não mencionou a freqüência de costelas das espécies do subgênero Toltecia, mas sua forma geral, traçado e disposição é similar ao de $P$. (T.) pilsbryi. O mesmo ocorre com P. minutissimum, para a qual SOLEM (1977) indica a ocorrência de costelas laminares baixas e um pouco sigmóides, as quais são mais baixas e menos inclinadas que as de $P$. (T.) pilsbryi e do que as daquelas espécies de Toltecia descritas por PILSBRY (1946), porém, identifica-se perfeitamente com o espécime de P. minutissimum de o próprio SolEm (1977) descreveu.

A microesculturação, observável à eletromicroscopia de varredura, compõe-se de microcostelas, que SCOTT (1957a) chamou de pregas, muito finas, tênues e paralelas, semelhantes às que ocorrem nas espécies examinadas por FONSECA (1994), no entanto são muito mais freqüentes. A microestriação é muito tênue e muito apertada, embora, segundo FONSECA (1994) não tanto como em Radioconus riochicoensis. Essas microestrias são, na verdade, fracas ondulações e sulcações do perióstraco, visíveis em 750X (Fig. 1e). SOLEM (1977: 151, Figs 5 , 6) também apresentou este tipo de microestriação para $P$. minutissimum. PILSBRY (1946) mencionou a ocorrência de uma estriação intercostelar delicada nas espécies de Toltecia. Quanto ao aspecto da coloração mais castanha e da microesculturação de $P$. (T.) conspectum conspectum, o perióstraco aproxima-se muito do da variedade "cleliae" de $P$. (T.) pilsbryi, mas na variedade de $P$. (T.) 
conspectum conspectum proveniente do Arizona e do Novo México, o perióstraco é mais amarelado e similar à variedade "misionensis". No caso de $P$. (T.) pilsbryi, essas variedades ("misionensis" e "cleliae") são simpátricas e não há como separá-las em subespécies. Há pouco tempo essas variedades eram consideradas espécies isoladas (SCOTT 1957a,b; WEYRAUCH 1965), mas devido à grande similaridade das conchas FONSECA \& THOMÉ (1994a) consideraram-nas como sendo a mesma espécie, somente estudos de anatomia interna poderão dizer se há ou não diferenças marcantes, com o que se possa efetivamente separá-las em espécies distintas, porém os estudos de FONSECA (1994) não indicaram haver tais distinções marcantes quanto aos sistemas excretor e reprodutor.

Diferente daquelas outras espécies de FONSECA (1994), a última volta é muito ampla e a abertura é mais circular que reniforme, como foi mencionado por SCOTT $(1957 \mathrm{a}, \mathrm{b})$. O peristômio apresenta-se como nas outras espécies: é simples e cortante. O umbílico é perspectivo mas se encontra um pouco mais estreito do que naquelas demais espécies, equivalendo a $1 / 5$ do D, embora SCOTT (1957a) tenha assinalado $1 / 4$ do D para esta espécie. Aquelas espécies do subgênero Toltecia, citadas por PILSBRY (1946) também apresentam umbílico variando de $1 / 4$ a $1 / 5$ do $\mathrm{D}$, ainda que $P$. (T.) vitreum apresente-o com pouco menos de $1 / 4$, por outro lado, o aspecto geral do umbilico de $P$. (T.) pilsbryi aproxima-se muito mais ao de $P$. (T.) conspectum.

No que diz respeito ao sistema excretor (Fig. 2a), o rim de $P$. (T.) pilsbryi é muito peculiar se comparado ao das espécies de Charopidae (Radioconus riochicoensis, "Radioconus" costellifer, Radiodiscus thomei, e.g., segundo FONSECA 1994), contudo é muito similar ao das espécies de Punctum, em especial P. (T.) conspectum jaliscoense (PILSBRY 1946: 641-2, Fig. 359c). Possui formato trapezóide e lado pulmonar profundamente escavado, formando uma fenda em que se aloja o ureter primário e a parte proximal do secundário, muito próximos entre si e aderidos à face uretal do rim. Essa formação faz com que o rim seja praticamente dividido em duas partes ou lobos segundo WÄCHTLER (1934), uma direita ou pericárdica e outra esquerda ou retal de tamanhos mais ou menos iguais. Essa forma foi observada por BAKER (1927) e SOLEM (1983) em Punctidae e por WÄCHTLER (1934) em Punctum, o que aproxima $P$. (T.) pilsbryi desse gênero e, conseqüentemente, da família Punctidae. Diferente das espécies de Charopidae, como foi mencionado anteriormente, a base (proximal) do rim não apresenta um aspecto muito diferenciado do da parte distal, o que é verificável na descrição de P. (T.) conspectum jaliscoense (sec. PILSBRY 1946). Este rim é grande em relação à cavidade palial, mas não é muito maior do que o das outras espécies, sendo praticamente do mesmo tamanho que daquelas espécies de Toltecia mencionadas por PILSBRY (1946).

A papila renal também se posiciona apicalmente na face uretal, mas ao contrário das outras espécie estudadas por FonSECA (1994) e FONSECA \& THOMÉ (1994b), está voltada mais para o lado pulmonar do que para o retal. Todavia, PILSBRY (1946) não faz menção à posição da papila renal nas espécies de Toltecia, mas a configuração do ureter primário na representação do sistema excretor (Fig.349e, p.642) indica que deve ser muito similar ao de $P$. (T.) pilsbryi. A 
disposição dos ureteres é similar à mencionada nos comentários de WÄCHTLER (1934) e NORDISIECK (1985), embora o ureter primário seja mais acentuadamente paralelo ao reto e não um pouco inclinado como ocorre nas outras espécies. O poro uretal possui uma posição mais proximal do que em Radioconus riochicoensis segundo FONSECA (1994) encontrando-se junto ao ápice da parte retal do rim e abrindo-se para o canal excretor. O ducto reno-pericárdico localiza-se numa pequena e débil prega da face pericárdica, na região mediana da aurícula. Essa prega, ainda que semelhante a que ocorre em Radioconus riochicoensis conforme FONSECA (1994) é muito inconspícua se comparada com a maioria das outras espécies, diferindo também em relação ao posicionamento que é mais distal ("Radioconus" costellifer) ou mais proximal (Radioconus riochicoensis), como mencionou FONSECA (1994). PILSBRY (1946) não citou ou posicionamento do ducto reno-pericárdico em $P$. (T.) conspectum jaliscoense.

O ureter primário é muito longo em relação ao das outras espécies examinadas por FONSECA (1994) e FonSECA \& THOMÉ (1994b), contudo mais afilado. $\mathrm{O}$ ureter secundário apresenta praticamente o mesmo comprimento e diâmetro, como foi observado por BAKER (1927) para os Punctidae, sendo que este ureter, por sua vez, e encurtado e relativamente menor em comparação ao das outras espécies comentadas, porém muito similar ao de $P$. (T.) conspectum jaliscoense.

Tal qual em Radioconus riochicoensis e semelhante ao descrito por BAKER (1927) para Radioconus bactricolus e por PILSBRY (1946) para as espécies de Toltecia, o ureter secundário continua-se, a partir do ápice da parte retal do rim, num canal excretor, contudo é mais longo e amplo que naquela espécie de BAKER (1927), chegando a corresponder à $2 / 3$ do comprimento da cavidade palial. O canal normalmente encontra-se encoberto por uma membrana, formando uma lamela que percorre o canal aderida à sua borda esquerda. A presença desse tipo de lamela precisamente não foi mencionada por BAKER (1927) nem por PILSBRY (1946).

O canal desemboca no sinus excretor, seu posicionamento é idêntico ao daquelas espécies examinadas por FONSECA (1994) e FONSECA \& THOMÉ (1994b), assim como o da abertura excretora. É um pouco raso porém mais nítido que em Radioconus riochicoensis e encontra-se parcialmente encoberto por uma membrana epitelial da prega do pneumostômio.

O sistema excretor de $P$. (T.) pilsbryi possui poucas afinidades com as outras espécies estudadas por FonSECA (1994) e FONSECA \& THOMÉ (1994b), bem porque estas são caropídeos, mas por outra lado é muito similar ao descrito por PILSBRY (1946) para o subgênero Toltecia, enquadrando-se no descrito por SOLEM (1983) para os Punctidae. Somente a distribuição geral das estruturas como rim, poro renal, papila renal, pericárdio, ureteres, sinus excretor e abertura excretora é semelhante ao que ocorre nos caropídeos. Difere desses em especial na forma do rim e do canal excretor com lamela bem desenvolvida, aspecto e posição do ducto reno-pericárdico, posição dos poros renal e uretal e tamanho dos ureteres. Há alguma semelhança com Radioconus riochicoensis e Radioconus bactricolus segundo FONSECA (1994) no que diz respeito à presença de canal excretor, bem como em relação ao aspecto e posição do ducto reno-pericárdico e 
posição do poro uretal de Radioconus riochicoensis (ainda que seja mais proximal em $P$. (T.) pilsbryi), contudo difere acentuadamente nas demais estruturas, particularmente na forma do rim, tamanho dos ureteres e posição da papila e do poro renal.

Quanto ao sistema reprodutor (Figs 2b-d), o ovariotestis de $P$. (T.) pilsbryi é composto de um só lobo muito desenvolvido em relação à glândula digestiva posterior (em que está embebido) e ao das demais espécies estudadas por FONSECA (1994) e FONSECA \& THOMÉ (1994b), assemelhando-se em tamanho ao lobo distal de $R$. riochicoensis. É a única espécie com ovariotestis monolobulado e compacto entre as estudadas. O que também difere do que PILSBRY (1946) mencionou para as espécies de Punctum e de SOLEM (1983) para os Punctidae. Radiodiscus thomei também apresenta ovariotestis compacto, contudo é muito mais reduzido e bilobulado como descreveram FonSECA \& THOMÉ (1994b). Já em Radioconus bactricolus o ovariotestis é trilobulado e racemoso (BAKER 1927, est. 17, Fig. 25). Nas outras espécies relacionadas no presente trabalho, é bi ou trilobulado e racemoso, tal como em Radiodiscus millecostatus, conforme BAKER (1927).

O posicionamento e $\mathrm{o}$ aspecto geral do ovulispermioducto são os mesmos que nas demais espécies estudadas por FonsECA (1994) e FONSECA \& ThOMÉ (1994b), contudo é curto em relação a essas mesmas espécies. Difere daquelas de BAKER (1927) somente no aspecto da vesícula seminal, a qual não é entrecontorcida como ocorre naquelas. A presença de ovulispermioducto "liso" foi assinalada como característica de Punctidae por SOLEM (1983). Apresenta-se dividido em seções: proximal, vesícula seminal e distal encurtada. Também é esbranquiçado e iridiscente tal qual nas outras espécies relatadas. Porém é muito similar ao das espécies de Toltecia mencionadas por PILSBRY (1946).

Apesar de não ser entrecontorcida, como foi comentado anteriormente, a vesícula seminal de $P$. (T.) pilsbryi é acentuadamente ondulada. Difere das outras espécies comentadas, cujo aspecto externo da vesícula praticamente não apresenta ondulações. Seu comprimento equivale, proporcionalmente, ao de Radioconus riochicoensis, mas é bem mais ampla. Como em todas as espécies relacionadas, a cor iridescente do ovulispermioducto acentua-se em sua superfície (FONSECA 1994; SOLEM 1983).

O complexo de fertilização é diminuto, embora não tanto quanto em "Radioconus" costellifer e Radioconus riochicoensis de acordo com FONSECA (1994). Externamente, apresenta-se composto por uma região proximal esferóide e um pequenino divertículo dorsal e distal (bolsa de fertilização), difere daquele de "Radioconus" costellifer pelo fato da bolsa ser mais proximal naquela espécie e a região que se comunica com a glândula do albume é muito mais débil, quase imperceptível em relação a essa de $P$. (T.) pilsbryi, que é esferóide e bem mais conspícua. Enquanto que em Radioconus riochicoensis, a bolsa não é distingüível à estereomicroscopia. Quanto às espécies de BAKER (1927), o complexo de fertilização em $P$. (T.) pilsbryi é muito menos conspícuo que em Radiodiscus millecostatus, mas possui alguma similaridade com o de Radioconus bactricolus, que também apresenta uma formação ovóide (BAKER 1927, est.17, Fig. 28), se bem que nessa espécie a bolsa de fertilização é bem mais destacada e proximal 
como foi mencionado para "Radioconus" costellifer segundo FONSECA (1994). O mesmo se verifica em $P$. (T.) conspectum jaliscoense, segundo PILSBRY (1946) e na descrição de SOLEM (1983) para os Punctidae.

A glândula do albume também é ovóide e posiciona-se como nas espécies de FONSECA (1994), contudo é um pouco mais deprimida, seu aspecto granuloso é mais fino e seus ácinos são muito indistintos. Por outro lado é muito semelhante à descrita por BAKER (1927) para Radioconus bactricolus (BAKER 1927, est.17, Fig. 25) è de $P$. (T.) conspectum jaliscoense segundo PILSBRY (1946). Em termos absolutos é praticamente do mesmo tamanho que a de Radioconus riochicoensis, mas é relativamente menor e também diferindo de forma acentuada no aspecto externo.

O ovispermioducto é normalmente longo e afilado, tal qual naquelas espécies examinadas por FONSECA (1994) e por PILSBRY (1946), contudo, ampliase enormemente quando o animal está em processo de segregação do ovo, como foi observado por FONSECA (1994) em um espécime de $P$. (T.) pilsbryi. O canal oviducal desenvolve-se muito, podendo ser chamado de incubador, no entanto não foi possível determinar se nessa espécie ocorre ou não ovoviviparidade. Vários autores, como BAKER (1927) e SOLEM (1983) denominaram essa parte do oviducto de útero ou região uterina, enquanto que outros, VISSER (1973) por exemplo, denominaram simplesmente de canal oviducal. Consideramos os argumentos de VISSER (1973) melhor embasados sobre a denominação correta das partes que compõem o ovispermioducto: sulcos (endo) espermático e alospermático e canal oviducal, contudo é notável que a denominação de BAKER (1927) para essa parte do ovispermioducto é totalmente válida em se tratando de espécimes comprovadamente ovovivíparas, ainda que a analogia com o útero dos mamíferos não seja muito adequada já que aquelas seções glandulares existentes no ovispermioducto, segundo VISSER (1973) não são homólogas aos anexos embrionários dos mamíferos. Dessa forma, acreditamos que o termo canal incubador é o mais apropriado para designar essa modificação do canal oviducal, no caso dessa espécie. Fora essa modificação, o ovispermioducto apresenta-se como nas outras espécies relatadas anteriormente, estando a glândula prostática aderida sobre a face dorsal. Em relação às de BAKER (1927), há diferenças no aspecto geral, pois esse ovispermioducto não apresenta ondulações regulares em sua superfície. Em relação à $P$. (T.) conspectum jaliscoense, o ovispermioducto é muito similar (PILSBRY 1946: 642, Fig. 349a), o qual também aparenta estar hipertrofiado.

Ao contrário do que ocorre com "Radioconus" costellifer, a glândula prostática não apresenta-se diverticulada, nem tão pouco dividida em duas partes como em Radioconus riochicoensis sec. FONSECA (1994). Sua forma também não é ovóide, ainda que seja deprimida. É curta, compacta e fortemente aderida à superfície do ovispermioducto, assemelhando-se um pouco com a de Radiodiscus thomei, embora seus ácinos sejam muito mais reduzidos e inconspícuos. Difere muito daquelas das espécies de BAKER (1927) e das de PILSBRY (1946), as quais apresentam-nas muito deprimidas, alveoladas e alongadas.

Nas demais espécies comentadas o oviducto é normalmente curto, com exceção de "Radioconus" costellifer em que é muito longo e bifurcado (FONSECA 
1994). Em P. (T.) pilshryi também é curto, porém não tanto quanto em Radiodiscus thomei conforme FONSECA \& THOMÉ (1994h). Seu aspecto interno não apresenta modificações peculiares, tanto em relação às outras espécies, há somente um sulco látero-dorsal que poderia ser parte do sulco alospermático, no entanto não foi possível determinar se isto é procedente. Difere dos das espécies de BAKER (1927), porque nelas o oviducto é longo. Todavia, é similar ao de $P$. (T.) conspectum jaliscoense conforme descrição de PILSBRY (1946).

O ducto e a bolsa da copulação posicionam-se tal qual naquelas outras espécies vistas por FONSECA (1994), contudo não foi observado nenhum divertículo, ou formação saciforme, associado à parte proximal do ducto dessa glândula, como foi mencionado por BAKER (1927) para aquelas duas espécies. O ducto e a bolsa possuem alguma semelhança de aspecto e tamanho com o que ocorre em Radiodiscus riochicoensis e Radiodiscus millecostatus, embora a bolsa desta última seja mais desenvolvida (FONSECA 1994). Quanto à $P$. (T.) conspectum jaliscoense, esse ducto é muito similar, apresentando a mesma dilatação proximal que em $P$. (T.) pilsbryi, o que também se adequa à descrição de SOLEM (1983) para os Punctidae.

Da mesma forma, a vagina apresenta variação apenas no tamanho (é muito afilada), se comparada com aquelas espécies de FonSECA (1994). No restante, inclusive internamente, apresenta-se muito similar, exceto, é claro, em relação à vagina de "Radioconus" costellifer, que faz parte da alça lateral do oviducto, bem como não apresenta as pilastras internas mencionadas por SOLEM (1983) para os Punctidae.

O ducto deferente é longo e afilado, apresenta inserções proximal, no início do oviducto, e distal continuando-se no epifalo, semelhante ao que ocorre naquelas espécies estudadas por FONSECA (1994), todavia é bem mais alongado e enquanto forma-se proximalmente na parede do início do oviducto, em Radioconus costellifer a inserção proximal encontre-se na curvatura proximal da alça lateral do oviducto; a parte distal dilata-se no epifalo, mas não tão acentuadamente como nas outras espécies relatadas. Também não apresenta inovações em relação aos comentários de BAKER (1927) e é muito similar ao de $P$. (T.) conspectum jaliscoense, segundo a descrição de PILSBRY (1946).

$\mathrm{O}$ epifalo também não apresenta inovações peculiares, inclusive internamente, em comparação às espécies examinadas por FONSECA (1994). É longo, sofrendo uma curvatura acentuada em que se insere o músculo retrator faliano, como nas outras espécies. Este músculo é longo e afilado, mas, relativamente, não tanto quanto em Radiodiscus thomei. Dilata-se no falo, logo após a inserção do músculo retrator, similar ao que ocorre em Radiodiscus thomei e não constituindo uma formação campanulóide como naquelas outras espécies de FONSECA (1994) e em Radiodiscus millecostatus; também não corresponde ao descrito por BAKER (1927) para Radioconus bactricolus, no qual o epifalo é muito longo e pouco amplo. PILSBRY (1946) mencionou que as espécies de Toltecia não apresentam epifalo distinto, sendo que Climo (1969) considerou que o epifalo é ausente em Punctinae. Essa simplicidade da genitália terminal foi atribuída por SOLEM (1983) como característica de Punctidae. Em $P$. (T.) pilsbryi o epifalo apresenta-se como uma 
simples dilatação, de forma leve, do ducto deferente.

O falo de $P$. (T.) pilsbryi apresenta-se um pouco reduzido embora seja alongado, podendo ser considerado eufálico, segundo a definição de TOMPA (1984), diferente do que ocorre com Radioconus bactricolus (BAKER 1927, est. 17, Fig. 25), mas também podendo ser considerado eufálico, e um pouco semelhante ao de Radiodiscus thomei, com o qual é comparativamente proporcional em comprimento (1/4 da extensão total do sistema reprodutor, segundo FonsECA 1994 e FonsECA \& THOMÉ 1994b). O falo apresenta-se muito similar ao de $P$. (T.) conspectum jaliscoense conforme descrição de PILSBRY (1946), em especial quanto à bainha faliana e à inserção do músculo retrator faliano. Porém, essa espécie mencionada por PILSBRY (1946) não apresenta uma campana como falo propriamente dito, mas sim uma projeção lingüiforme que separa a parte proximal do falo em duas pequenas câmaras (sic PILSBRY 1946). Essa projeção é descrita como uma papila terminal por SOLEM (1983), que ocorre no falo dos Punctidae. Todavia, não se verificou a presença de papilas ou rugosidades internas na bainha de $P$. (T.) pilsbryi como ocorre em $P$. (T.) conspectum jaliscoense, nem mesmo daquela projeção terminal. No aspecto geral, o falo (evertofalo) difere muito em comparação com as outras espécies de Charopidae sec. FonSECA (1994) e FonsECA \& ThOMÉ (1994b), pois enquanto é piriforme, curto e amplo nessas espécies, é fusiforme, afilado e alongado. Por outro lado, na face interna seu aspecto geral e o falo propriamente dito (campana) igualmente não apresentam aspectos peculiares, ou estruturas como aquela pilastra da bainha do falo de Radioconus bactricolus de acordo com BAKER (1927) e a de "Radioconus" costellifer sec. FONSECA (1994).

Punctum (T.) pilsbryi é sintremado, o átrio genital, assim como em todas as espécies já mencionadas, é muito curto e dilata-se levemente abrindo-se pelo poro genital único, que se posiciona na face lateral direita da região cefálica, junto ao cmatóforo direito.

\section{CONCLUSÕES}

Como havia sido comentado por BAKER (1927), PILSBRy (1946), SolEM (1976, 1977, 1983), a conquiliometria e as esculturações da concha, em especial as microesculturações (microestrias, costeletas, microcostelas, sulcações e protuberâncias do perióstraco) fornecem dados diagnósticos básicos para a determinação das espécies em nível da família e gênero. Ficou comprovado, que também em nível de subgênero e de espécie, como consta de FonsECA (1994) e FonsECA \& THOMÉ (1994b), as características conquiliomorfológicas são fundamentais para a determinação desses táxons. No caso de P. (Toltecia) pilsbryi (Scott, 1957) as características diagnósticas são, basicamente, concha com 3 e $1 / 2$ a 4 voltas em até $2,4 \mathrm{~mm}$ de diâmetro, esculturada por costelas laminares simples e levemente inclinadas; protoconcha com 15 a 17 estrias nepiônicas. Contam-se 10 costelas em $500 \mu \mathrm{m}$, uma microcostela a cada $9 \mu \mathrm{m}$ e uma microestria a cada $7 \mu \mathrm{m}$. O perióstraco varia de amarelado a castanho-ocre, opaco ou semitransparente (FONSECA \& THOMÉ 1994a); o umbílico é muito aberto e com aspecto perspectivo. A abertura 
é circular e ampla diferenciando-se das espécies de Charopidae (com exceção de "Radioconus" costellifer), mas assemelhando-se ao das demais espécies de Toltecia.

Sistema excretor de $P$. (T.) pilsbryi apresenta rim característico do gênero; os ureteres escavam profundamente o lado pulmonar e dividem o rim em duas partes: uma pericárdica e outra retal; ureter secundário curto, continuando-se num longo canal excretor, ladeado por uma lamela muito fina; sinus e abertura excretora nítidos. Essa forma do rim peculiar de $P$. (T.) pilsbryi é própria gênero Punctum conforme observação de WÄChtler (1934), PILSBRY (1946) e de FOnSECA (1994); o que aproxima esta espécie da família Punctidae (BAKER 1927; SOLEM 1983), aliado às características da concha e do sistema reprodutor (FONSECA 1994), devendo, portanto, ser classificada nessa família dentro de Punctum e do subgênero Toltecia Pilsbry, 1926.

Sistema reprodutor apresentando ovariotestis monolobulado e consistindo de um lobo compacto; a glândula do albume também apresenta-se mais compacta se comparada às das outras espécies relacionadas. Ovispermioducto freqüentemente hipertrofiado, tal qual fora mencionado por BAKER (1927), PILSBRY (1946) e debatido por VISSER (1973), com o canal oviducal desenvolvido num canal incubador, como consta de FONSECA (1994). Glândula prostática reduzida, compacta e deprimida. Oviducto muito curto mas a vagina é alongada; o falo (evertofalo) é um pouco afilado e fusiforme, apresentando falo propriamente dito (campana) reduzido. A inexistência de papilas ou rugosidades na bainha faliana denota uma simplificação maior dessa região em relação àquelas espécies estudadas por BAKER (1927), PILSBRy (1946) e por FonseCA (1994).

As características principais do sistema excretor como forma do rim e disposição dos ureteres (mencionadas por BAKER 1927; WÄCHTLER 1934; SOLEM 1983; FONSECA 1994), e do sistema reprodutor - com exceção do ovariotestis monolobulado, citado por FONSECA (1994); das rugas internas e da projeção terminal do evertofalo, mencionadas por BAKER (1927), PILSBRY (1946) e SOLEM (1983) - devem ser usadas como características diagnósticas para a determinação

das espécies de Punctum e em conseqüência dos Punctidae ocorrentes na América do Sul, assim como na América do Norte.

AGRADECIMENTOS. A Cleodir José Mansan, pelo auxílio na microscopia eletrônica, do Museu de Ciências Naturais da Fundação Zoobotânica do Rio Grande do Sul. Porto Alegre.

\section{REFERÊNCIAS BIBLIOGRÁFICAS}

Baker, H.B. 1927. Minute Mexican Land Snails. Proc. Acad. nat. Sic. Philad. 79: 223-35.

Climo, F.M. 1969. Classification of New Zealand Arionacea (Mollusca: Pulmonata) I. The higher Classification. Records of the Dominion Museum, Wellington, Nova Zelândia, 6 (12): 145-158.

1978. Classification of New Zealand Arionacea (Mollusca: Pulmonata). A review of the New Zealand charopine snails with lamellate apertures. 
Records of the Natural Museum of the New Zealand 1 (12): 177-201.

FONSECA, A.L.M. 1994. Conquiliomorfologia e anatomia dos sistemas excretor e reprodutor de Radioconus costellifer (Scott, 1957); Radioconus pilsbryi (Scott, 1957); Radioconus riochicoensis (Crawford, 1939); Radiodiscus thomei Weyrauch, 1965 e Retidiscus reticulatus Fonseca \& Thomé (no prelo a). Dissertação de Mestrado, não publicada, Instituto de Biociências, Pontifícia Universidade Católica do Rio Grande do Sul, Porto Alegre, 142p.

FonseCA, A.L.M., J.W. Thomé. 1993a. Descrição de Glabrogyra subgen.n., recaracterização de Austrodiscus twomeyi (Parodiz, 1954) e reclassificação das espécies sulamericanas dos gêneros Austrodiscus Parodiz, 1957, Radioconus Baker, 1927, Radiodomus Baker, 1930 e Trochogyra Weyrauch, 1965 (Charopidae) e Zilchogyra Weyrauch, 1965 (Helicodiscidae). Iheringia, sér. Zool., Porto Alegre, (75): 97-105.

. 1993b. A classificação das espécies neotropicais de micromoluscos dos gêneros Stephanoda Albers, 1860, Stephadiscus Scott, 1981 e Ptychodon Ancey, 1888. Acta Biologica Leopoldensia, São Leopoldo, 15 (2): 65-76.

FonseCA, A.L.M., J.W: ThOMÉ. 1994a. Descrição de Radiodiscus vazi n. sp. de São Paulo, Brasil, com proposição de recombinação de duas outras espécies sob este gênero e Radioconus bolachaensis n.n. e sinonimização de uma espécie de Radioconus Baker, 1927. Revta bras. Zool. 11 (2): 265-275.

. 1994b. Conquiliomorfologia e anatomia dos sistemas excretor e reprodutor de Radiodiscus thomei Weyrauch, 1965. Biociências, Porto Alegre, 2 (1): 163-188.

NORDSIECK, H. 1985. The system of Stylommatophora (Gastropoda), special regard to the systematic position of the Clausiliidae. Arch. Molluskenk., Frankfurt, 116 (1-3): 1-24.

Parkinson, B.; J. Hemmen \& K. Groh. 1987. Tropical Landshells of the World. Wiesbaden, Christa Hemmen, 297p.

PILsBry, H.A. 1946/48. Land Mollusca of North America (North of Mexico). Philadelphia, Academy of Natural Sciences of Philadelphia, v. 2, part.1-2, $653 p$.

RIEDEL, A. \& A. WIKTOR. 1974. Arionacea: limaki krazatkowate i linikowate (Gastropoda, Stylommatophora). Fauna Polski, Varsóvia, 2: 1-141.

SCOTT, M.I.H. 1957a. Endodóntidos Neotropicales I. Neotropica, Buenos Aires, 3 (10): 7-16.

1957b. Endodóntidos Neotropicales II. Neotropica, Buenos Aires, 3 (12): 79-87.

-1964. Helix costellata d'Orbigny a la luz de su Anatomia. Neotropica, Buenos Aires, 10 (31): 15-19.

SCOTT, M.I.H. 1968. Endodóntidos Neotropicales III. Neotropica, Buenos Aires, 14 (45): 99-102.

1970. Endodóntidos de la Región Austral Americana. Revta Mus. argent. Cienc. nat. Bernardino Rivadavia Inst. nac. Invest. Cienc. nat., Buenos Aires, 10 (18): 267-96. 
SOLEM, A. 1976. Endodontoid Land Snails from Pacific Islands (Part I: Family Endodontidae). Chicago, Field Museum of Natural History, 508p.

- 1977. Shell microsculpture in Striatura, Punctum, Radiodiscus and Planogyra. Nautilus, Silver Springs, 9: 149-55.

- 1983. Endodontoid Land Snails from Pacific Islands (Part II: Families Punctidae and Charopidae, Zoogeography). Chicago, Field Museum of Natural History, 336p.

TOMPA, A.S. 1984. Land snail (Stylommatophora). In: K.M. WILBUR (ed.). The Mollusca. Orlando, Academic Press, 7, 486p.

VAZ, J.F. 1991. Observações Anatômicas em Helicodiscinae (Endodontidae; Pulmonata) com adescrição de uma nova espécie. Rev. Brasil. Biol., Rio de Janeiro, 51 (1): 277-84.

VISSER, M.H.C. 1973. The ontogeny of the Reproductive System of Gonaxis gwandaensis (Preston) (Pulmonata, Streptaxidae) with special reference to the phylogeny of spermatic conduits of the Pulmonata. Annale Universiteit van Stellenbosch, Ser. A, Cape City, 48 (4): 1-79

WÄCHTLER, W. 1934. Der Nierenapparat der stylommatophoren Lungenschnecken, vergleichend anatomisch betrachtet. Zool. Anz., Leipzig, 105 (7-8): 161-171.

Weyrauch, W.K. 1965. Neue und verkannte Endodontiden aus Südamerika. Arch. Molluskenk., Frankfurt, 94 (3/4): 121-34.

Recebido em 02.VIII.1994; aceito em 08.III.1995. 